\title{
An Investigation of Perceptions of Vietnamese Teachers and Students toward Cooperative Learning (CL)
}

\author{
Pham Thi Hong Thanh \\ School of Education, Level 4, Social Sciences Building (\#24) \\ The University of Queensland, St Lucia, Qld 4072, Australia \\ Tel: 61-7-3365-6550Ｅ-mail: s4088650@student.uq.edu.au
}

\begin{abstract}
The present study examined how cooperative learning (CL) is implemented in Vietnamese classrooms, how local teachers' and students' perceived this approach to learning, and what were the local barriers that hindered its implementation. Forty teachers and forty students from twenty Vietnamese colleges completed a questionnaire about $\mathrm{CL}$ and follow-up interviews were conducted with ten students and ten teachers on their perceptions of this practice. The results showed that CL has become a common and preferred method of instruction in Vietnam. However, the functions of CL were often not understood correctly because the teachers and students maintained that CL mainly helped the students remember information rather than develop a deep understanding of the text they were studying. Responses also revealed that CL was hindered by a number of local cultural and institutional barriers such as class size, curriculum coverage and workload division. Future research may need to identify strategies to correct mismatches between CL principles and local barriers so that this approach to learning becomes more adaptive to the local context.
\end{abstract}

Keywords: Vietnam, Cooperative learning, Cultural barriers, Institutional barriers

\section{Introduction}

Asian students' approaches to learning started to attract the attention of researchers in the late 1980s and early 1990s. In general, there are differing points of view about Asian students' approaches to learning. On one side, various researchers in the field (e.g., Gow \& Kember, 1990; Go \& Mok, 1995) argue that Asian students are deemed to be passive recipients of knowledge and, consequently, have had little experience in studying independently. It is argued that this habit prevents these students from exploring extra knowledge beyond textbooks so that when they have to cope with tasks requiring deep understanding, Asian students are thought to be at a distinct disadvantage as many of them encounter great difficulty in isolating and interpreting information.

In contrast, many Asian students study very successfully in Western universities. In fact, they consistently outperform their Western counterparts in their home country and in overseas universities (Biggs, 1998). This fact led to Biggs (1996) and Marton and Saljo (1996) to question the belief that Asian students only learn by rote (as a mindless machine) because they would certainly not succeed in exams in Western universities if they were only learning by rote as research has shown that students who rote learn do not demonstrate achievement (Biggs, 1998). Consequently, it appears difficult to argue that Asian/Vietnamese students learn only by rote.

While arguments about the true nature of Asian students are still inclusive, in general, researchers have agreed that the only difference between Western learners and Asian learners is that while Western students often attempt to relate new information to previous or other knowledge or to make sense of new information in the light of personal or real life experiences, Asian learners seem to understand information only contained within the text, or that which is supplied by the lecturer (Tang, 1991; Gow \& Kember, 1990). Asian learners appear not to use such elaborative processes as critically analyzing new information or relating it to other subject matter. This is unfortunate because it is these skills that limit Asian/Vietnamese students' performance in today's global economy where individuals are expected to be able to critique information in the light of current or previous understandings and develop solutions. It is because of the apparent need for these skills that teachers are being pressured to change from the traditional approach to learning to develop these skills while ensuring that they continue to maintain high academic standards for their students.

Consequently, similar to many Asian countries since the early 1990s, Vietnam has been pressured to carry out a series of educational reforms to adopt CL as priority pedagogy to replace the traditional teaching approach. Since these reforms were launched, there have been a number of changes in the Vietnamese education system and Vietnamese teachers and students have become very familiar with Western teaching and learning approaches such as group-work, seminar presentations, team activities and especially CL. However, very few studies have 
investigated how the Vietnamese education system has changed; what Vietnamese teachers and students think about practices imported from the West; and what are the barriers hindering the implementation of these practices.

It is important to investigate these issues because Thanh-Pham, Gillies and Renshaw (2009), in a study which reviewed a series of studies on CL in non-Western countries, found that more than fifty per cent reported that CL was no better and even worse than the traditional lecture-based teaching method in terms of increasing students' academic achievement. The present study attempts to provide an over view of how CL has been conducted in Vietnamese colleges, how teachers and students perceive this approach to learning and what are the barriers that hinder the application of this pedagogical practice. Specifically, the study is guided by the following three questions:

How is CL implemented in Vietnamese classes?

What are Vietnamese teachers' and students' perceptions of CL?

What are the barriers to implementing CL in Vietnamese classes?

This study is the exploratory phase of a three-year project that the researcher is conducting under the auspices of the University of Queensland, Australia. It aims to determine effective strategies to make a CL more adaptive in non-Western countries [Vietnam included].

\section{Method}

\subsection{Participants}

Participants included forty teachers (thirty females and ten males) and forty students (twenty five females and fifteen males) from twenty universities around HoChiMinh City, Vietnam. The teacher participants ranged from thirty to forty years of age and had five to ten years of experience in teaching different social subjects at university. The student participants were university students and ranged eighteen to twenty two years of age.

These teachers and students were invited to participate in the study when they attended the National Conference on Education in HoChiMinh City, Vietnam. All teacher and student participants completed a questionnaire on their experiences of all CL practices they have used, and their attitudes toward this method and barriers they encounter when they implement CL in their classes. Ten teachers and ten students were chosen randomly to participate in follow-up, in-depth interviews on their experiences with CL. Interview questions focused on examining their perceptions of CL's functions and barriers hindering CL practices. All interviews were completed within a day. Each interview lasted for 15-30 minutes.

\subsection{Data collection methods}

Data were collected via two different sources: a questionnaire survey and interviews.

Questionnaire: The questionnaire consisted of two parts. The first part included items investigating the participants' perceptions about frequency and procedures of CL applied in their classes and their attitudes toward this learning method. The questionnaire was self-administered because it was not possible to identify an instrument from the literature that allowed the first researcher to capture all the variables involved in this study. Some of items in the questionnaire were: "How often do you have CL in your class?"; "Cooperative learning is effective"; and "Cooperative learning improves students' knowledge and soft skills like self-confidence and communication".

The second part consisted of open-ended items which aimed at investigating students' perceptions of barriers preventing the application of CL in Vietnamese classrooms. Some questions in this part were: "What barriers do you think prevent CL activities in your class? Explain" and "What problems do you often cope with when you work in groups in a large class?" (see Appendix 1).

Interviews: At the completion of the conference, ten students and ten teachers were chosen randomly to participate in one-by-one interviews. An assistant was employed to help the first researcher with conducting interviews and she was given a list of questions, prepared by the first researcher, to ask each participant. We utilized a semi-structure interview scheme with a number of guiding questions. Examples were: "What do you think about CL?" "What are difficulties you often face when you apply CL?" and "How do your group members share ideas?" (see Appendix 2 and 3 for a list of the questions).

\subsection{Data analysis}

Questionnaire: Participants were asked to circle their response among five options on two scales: always, often, sometimes, seldom, never or strongly agree, agree, undecided, disagree and strongly disagree. Data were analyzed using SPSS 18.0. Prior to analysis, all variables were examined for accuracy of data entry. Since this study aimed to explore general views of the participants about CL, simple calculations were applied to report responses in terms of the percentage format. 
Interviews: Content analysis procedures were applied (Neuman, 2003). First, data were disentangled into segments (this can be a word, a single sentence or a paragraph) so that annotations and codes could be attached to them. After codes were developed, codes around phenomena discovered in the data were grouped into categories which were more abstract. Finally, categories were quantified in the form of frequencies or converted into percentages. The excerpts quoted in the paper are referenced with interview numbers and line numbers in the transcripts. For example, I2L15/20 means that the quotation is from line 15 to 20 in the transcripts of interview 2.

Results

\section{Frequency and procedures of CL}

1. How often do you have cooperative learning in your class?

$\begin{array}{llllll} & \text { Always } & \text { Often } & \text { Sometimes } & \text { Seldom } & \text { Never } \\ \text { Teachers: } & 20 \% & 38 \% & 22 \% & 17 \% & 3 \% \\ \text { Students: } & 20 \% & 35 \% & 15 \% & 18 \% & 12 \%\end{array}$

2. Formats of CL used in class

a. The teacher announces the topic. Then, students choose group members to discuss the topic and then report to the class.

$\begin{array}{llllll} & \text { Always } & \text { Often } & \text { Sometimes } & \text { Seldom } & \text { Never } \\ \text { Teachers: } & 20 \% & 45 \% & 25 \% & 10 \% & 0 \% \\ \text { Students: } & 15 \% & 35 \% & 42 \% & 8 \% & 0 \%\end{array}$

b. The teacher announces the topic. Students choose group members and then the teacher assesses the group work.

$\begin{array}{llllll} & \text { Always } & \text { Often } & \text { Sometimes } & \text { Seldom } & \text { Never } \\ \text { Teachers: } & 25 \% & 30 \% & 20 \% & 12 \% & 13 \% \\ \text { Students: } & 7 \% & 32 \% & 31 \% & 10 \% & 20 \%\end{array}$

c. The teacher announces the topic, assigns students to groups, instructs students to work in groups asks students to evaluate each other, and assess the group product.

$\begin{array}{llllll} & \text { Always } & \text { Often } & \text { Sometimes } & \text { Seldom } & \text { Never } \\ \text { Teachers: } & 5 \% & 10 \% & 30 \% & 35 \% & 20 \% \\ \text { Students: } & 5 \% & 15 \% & 10 \% & 35 \% & 35 \%\end{array}$

Responses from the teachers and students in the questionnaire revealed that CL has been widely used in Vietnamese classes. Eighty percent of the teachers and $70 \%$ of the students said that CL has been 'always' 'often' and 'sometimes' used in their classroom. Impressively, no teacher and no student responded that their classes 'never' used CL.

For the question related to formats of $\mathrm{CL}$, responses from participants showed that the teachers did not follow any specific procedures when they implemented CL. When the participants were asked to choose formats of CL which were usually applied, only $45 \%$ of the teachers stated that they "always", "often" and "sometimes" applied the last format "The teacher announces the topic, assigns students to groups, instructs students to work in groups asks students to evaluate each other, and assess the group product". This format is generally considered the best way to establish CL. A majority of the teachers reported that they often applied the first and the second formats $(90 \%$ and $75 \%$ respectively). These two formats allowed the teachers to play a minimal role in instructing students to discuss their work in groups. Responses from the students even showed the application of the last format was rarer. Only $30 \%$ of the students agreed that their teachers "always", "often" and "sometimes" applied this format. $90 \%$ and $70 \%$ of the students said that the first two formats were "always" "often" and "sometimes" were applied in their classes.

Interview data: Responses also showed that $100 \%$ of the teachers explained that they had 'no choice' but had to implement CL because they were 'compulsorily' encouraged to get rid of the teacher-centered approach and employ student-centered approaches such as team discussions and seminars.

Now we are quite familiar with conducting group work in class, especially in social art subjects because it is easier to organize team work for these subjects (I1L10/13).

We cannot say 'no' to group work because it is compulsory to employ these activities in any class (I2L20/22). 
Similarly, $100 \%$ of the students confirmed that their classes often had group activities such as doing group exercises and presenting team products.

Attitudes toward CL

1. Cooperative learning is effective.

$\begin{array}{lllllc} & \text { Strongly Agree } & \text { Agree } & \text { Undecided } & \text { Disagree } & \text { Strongly Disagree } \\ \text { Teachers: } & 5 \% & 35 \% & 25 \% & 15 \% & 20 \% \\ \text { Students: } & 10 \% & 25 \% & 40 \% & 15 \% & 10 \%\end{array}$

2. Cooperative learning improves students' knowledge and other skills like self-confidence and communication.

\begin{tabular}{|c|c|c|c|c|c|}
\hline & Strongly Agree & Agree & Undecided & Disagree & Strongly Disagre \\
\hline Teachers: & $20 \%$ & $35 \%$ & $30 \%$ & $17 \%$ & $8 \%$ \\
\hline Students: & $22 \%$ & $28 \%$ & & $25 \%$ & $13 \%$ \\
\hline
\end{tabular}

3. I want to apply cooperative learning in my class.

\begin{tabular}{|c|c|c|c|c|c|}
\hline & Strongly Agree & Agree & Undecided & Disagree & Strongly Disagree \\
\hline Teachers: & $20 \%$ & $63 \%$ & $15 \%$ & $2 \%$ & $0 \%$ \\
\hline Students: & $25 \%$ & $55 \%$ & & $12 \%$ & $8 \%$ \\
\hline
\end{tabular}

Only $40 \%$ of the teachers and $35 \%$ of the students strongly agreed and agreed that CL was effective. The remaining of $60 \%$ of the teachers and $65 \%$ of the students reported they did not see CL as better than other teaching methods. However, $55 \%$ of the teachers and $50 \%$ of the students did agree that CL improved their personal skills such as self-confidence and communication skills.

Interview data: Interview responses discovered an interesting function of CL. When the participants were asked about what CL helped them the most, it was surprising to discover that $78 \%$ of them perceived that CL mainly aimed to help students remember the text, not to gain a deep understanding of the text or find connections between what was taught in the class and the application in the reality. This may be because teachers were always afraid that students would not understand new concepts and ideas if they did not explain them to them.

I usually lectured more when we had new lessons but asked students to work in groups when they had to do homework. It was hard for students to understand new concepts without explaining to them (I1L22/25).

Perhaps the teachers' thoughts heavily affected students' learning habits because many students perceived that the teacher must play the main role in lecturing and explaining new knowledge to them. Seventy-seven percent of the students agreed that friends could help each other to remember the text but could not help teach each other to understand new lessons.

We could read the text by ourselves but sometimes we could not help each other understand new definitions or the figurative meaning of some concepts (I6L8/10).

Responses of the students showed that there were two main reasons why the students persistently needed the teacher's instruction and explanations for important points. First, the students had been conditioned to accept that "the teacher' words were always correct and friends' words were for consultancy only". Second, the students were worried about seeking correct information for coming tests. In their thoughts, correct answers always came from two sources: "texts" and "the teacher's lecturing". The importance of this issue was highlighted because e $88 \%$ of the students made this comment.

Similarly, one of the open-ended questions in the questionnaire asked the students about how they learned to cope with exams and $60 \%$ of them reported that they usually tried to remember key points from the text and also took careful note of what the teacher said in class because they knew that many examination questions did not come from the text but came from the teacher's words.

Barriers hindering CL

Data obtained from both open-ended questions in the questionnaire survey and interviews indicate that CL was hindered by a number of factors in the local context. Based on themes emerging from the coding, these factors were grouped into five main categories: class size, curriculum coverage, group work division, material limitations and face-to-face discussions as presented in Table 1.

\section{Insert Table 1}




\section{Discussion}

\subsection{Teaching and learning}

The findings in this study are different from what others often refer to as teaching and learning in Asian countries where "The teacher reads and students write". In fact, it seems that CL has been widely implemented although the teachers were still very unclear about the procedures of organizing CL properly. It appears that the teachers just announced the topic and students were provided with limited guidance during their discussions. Perhaps the teachers usually organized group work spontaneously with a main purpose of changing the learning atmosphere only. Such unprepared procedures certainly affect the effectiveness of CL because a number of researchers have claimed that if teachers and students are passively involved in doing team works, group products are not effective (Johnson \& Johnson, 1990; Gillies, 2003, 2004). This may explain why $60 \%$ of the teachers and $65 \%$ of the students responded as they did and did not see or did not agree that CL was more effective than the traditional teaching and learning approach.

Interestingly, both the teachers and students revealed that CL tends to help students review and memorize what has been taught rather than to seek new knowledge. The participants' responses confirmed the traditional perception of the teacher as being an ultimate source of knowledge with the stream of knowledge following a one-way-street from the teacher to students. Traditionally, in Vietnamese classes, the teacher is considered to be a guru who is supposed to satisfy learners in the search for the truth (in knowledge) and virtues (in life) (Phuong-Mai, Terlouw and Pilot, 2006, Thanh-Pham, 2008). Teachers are dominant in the classroom and knowledge is transferred from the teacher to the students. Students are not confident to write down what does not emanate from the teacher. Therefore, students believe that they must memorize all the information that was presented in class if they want to pass the exams. Interestingly, what was reported in this study seems to be in contrast to what happens in constructivist classrooms where the teacher only plays the role of a facilitator.

A positive point is that both teachers and students showed their preference to CL. Their preference for CL is consistent with findings from prior research which claims that Asians prefer working in groups (Earley, 1993, 1994) and Asian learners favor group learning activities (Park, 2002). The enthusiasm to engage in group learning can be seen as a good starting point for the integration of $\mathrm{CL}$ into the Vietnamese curriculum, lesson design, teaching and learning pattern.

\subsection{Barriers of $C L$}

When endeavoring to apply CL, local teachers and students face various constraints associated with infrastructure, curriculum coverage, workload division, face-to-face discussion confrontation and material limitations. Class size and noise are the first stumbling blocks that both teachers and students have to surmount in order to implement CL. Class size in Vietnam varies depending on the subjects and the location of the college. For instance, college classes commonly have 30-40 students in natural science subjects and can rise to over 100 in social arts subjects. On average, Kirkpatrick (1998) claims that Vietnamese classes contain 50-70 students. In such big classes, if students are divided in groups of four or five, there would be 13-14 groups working simultaneously and teachers would not have enough time to exam/monitor each group to ensure they were working effectively. This has been reported to be not only the first and foremost problems in Vietnam but also in many other Asian countries where there is little possibility of reducing class sizes.

Curriculum coverage has resulted from the pressure on quantitative measurements which strongly focus on the amount of studying but not on the quality of studying. Biggs (1995) claims that curricula in Asian [Vietnamese included] schools are designed in a particular quantitative format which sees "any topic as important as every other topic, so that everything is taught and the student is grossly overloaded" (p.41). Due to such coverage, in class, Vietnamese teachers just have enough time to go through all materials but not investigate students' deep understanding or touch on any topics outside the curricula. As a result, all students can do at the end of each semester is to try to memorize what is covered in the curricula or what teachers said in class so that they can pass the exams. The consequence of such quantitative broad-based curriculum and a "didactic spoon-feeding" approach is that students are limited in developing deep understandings or thinking critically as they proceed through the program (Kember, 2000, p. 108). This situation is obviously ineffective for learning because a deep understanding of what is taught should be "a systematic goal for all students, not the fortuitous happenstance for a lucky few" (Biggs, 1995, p. 41).

Reading limitation is another factor keeping Vietnamese students away from independent learning. Materials are generally in short supply at all Vietnamese education institutions. Almost all Vietnamese universities have so far used text books as the unique information resource. Therefore, students perceive that the required text for a particular subject by the lecturer is the definitive written resource for that subject, and they do not need to consult 
any other information resource. Material limitations create two chances for students to become rote and surface learners. First, as the readings are very limited (one or two textbooks for a subject), teachers usually tell students exactly what to read and what needs more attention, if not memorized carefully, as these sections are likely to be questioned in the exams.

Second, limited readings turn Vietnamese classes into places where usually only one point of view is presented. There are no other perspectives for comparison. This implicitly tells students that there is only one right answer, so they do not have to question and discuss any point of view presented by the teacher or written in the textbook. In other words, teachers and institutions do not respect casual and analytic skills (Nisbett, 2003). This leads to a problem with Vietnamese students often persisting with intensive study and memorization of texts and lecture notes rather than trying to question, discuss and develop different points of view. In fact, this is one of the reasons why it is claimed that Asian [Vietnamese included] students rely too much on books, not taking responsibility for their own learning and not understanding the concept of plagiarism (Robertson, Line, Jones \& Thomas, 2000).

Group working culture is another type of barrier. Many studies on group work in Asian countries found that a harmonious atmosphere is a condition for effective group work (C. Chen, X. Chen \& Meindl, 1998; Sama \& Papamarcos, 2000). To maintain good relationship among members, students are very reluctant to initiate comments or reveal their own opinions. In the interview, many students stated that some time they were not quite sure of their group members' explanations but they still had to "nod their head" because if they strongly protested, they would destroy the group's good mood. This finding accords with previous research which has shown that harmony reigns supreme in Asian society (Hofstede \& Hofstede, 2005; Jia, 2001) and Asian students may be willing to sacrifice their personal feeling for the sake of the group (Triandis, 1995). This attitude militates against one of the advantages of CL which aims to create opportunities for students to discuss issues face-to-face to find the best answer.

Furthermore, workload envy is a controversial issue among Vietnamese learners. This issue attracted a lot attention from both teachers and students. Eighty-eight percent of the student participants recognized the problem of inequalities in the distribution of workload. Some students complained that some members were not willing to complete the group's task and became free riders in the process. Capable students expressed special concern about this issue. They complained that their friends were not helpful and they carried almost all the work for the group.

Slavin (1992) referred to this problem as a diffusion of responsibility. This occurs when group members have low individual accountability. This seems to be a common problem among groups in Vietnamese schools, mainly because students are often not well instructed in how to avoid this problem. Additionally, the teachers also maintained that the lack of guidance on how to establish small group learning was also a concern. They did not have many materials to consult and to guide them to solve group work problems. This might help to explain why the teachers were unable to help their students manage problems related to sharing their work, mutual teaching and reducing "social loafing".

\section{Conclusion}

In general, educators should find the results of this study encouraging. Results suggest that Vietnamese teachers and students are willing to adopt cooperative learning activities. Furthermore, it also suggests that cooperative learning can improve the social and personal skills of students. It is very encouraging to see that the students are glad to participate in this activity.

The study also identified a number of cultural and institutional barriers which hinder the implementation of cooperative learning in Vietnamese classes. It appears impossible to sweep away these barriers because some of them are cultural heritages which seem hard to be changed or removed, and others are institutional barriers which are beyond the capacity of both teachers and students to change. Therefore, to conduct cooperative learning effectively in the local context, the study suggests that it may not be appropriate to impose so-called Western practices on local students. Rather, there must be adjustments of such practices to make them more adaptive to the local context.

In later phases of the project, the first researcher found that for cooperative learning to work effectively in the Asian/Vietnamese context, researchers need to address disjunctions between cooperative learning and the local culture and infrastructure conditions. Some of these disjunctions can be seen, for example: While CL aims to encourage students to open up their own ideas and develop creativeness, Asian learners were not comfortable with questioning, evaluating, and generating knowledge ( $\mathrm{Hu}, 2002)$; while face-to-face interaction is emphasized as a main component of CL (Johnson \& Johnson, 1999), the deep-seated perception of 'surviving in harmony' strongly hindered Asian students from exchanging true opinions (Hofstede \& Hofstede, 2005); and while friendship groups were preferred among Asian students CL researchers appreciate mixed-ability grouping (Watson \& Marshall, 1995). In short, CL has a number of principles which are incongruent with the norms and values of non-Western cultures. 
Therefore, educators need to address: how to change some cooperative learning principles in ways that suit the local culture and the learning resources and how to change some local values to a way supporting cooperative learning.

\section{References}

Biggs, J. (1995). Student approaches to learning, constructivism and student-centered learning. Paper presented at the Improving university teaching: Twentieth International Conference 10-13 July, City University of Hong Kong.

Biggs, J. (1996). Western misconceptions of the Confucian-heritage learning culture. In D.A. Watkins \& J.B. Biggs (Eds.), The Chinese learner: cultural, psychological, and contextual influences (pp.45-67). Hong Kong: CERC and ACER.

Biggs, J. (1998). Learning from the Confucian Heritage: So size doesn't matter? International Journal of Educational Research, 29, 723-738.

Chen, C.C., Chen, X.P. \& Meindl, R.J. (1998). How can cooperation be fostered? The cultural effects of individualism-collectivism. The academy of management review, 23(2), 285-304.

Earley, C. (1993). East meets West meets Mideast: Further explorations of collectivistic and individualistic work groups. Academy of Management Journal, 36, 319-348.

Earley, C. (1994). Self or group? Cultural effects of training on self-efficacy and performance. Administrative Science Quarterly, 39, 89-117.

Gillies, M.R. (2004). The effects of communication training on teachers' and students' verbal behaviors during cooperative learning, International Journal of Educational Research, 41, 257-279.

Gillies, M. R. (2003) 'The behaviors, interactions, and perceptions of junior high school students during small-group learning', Journal of Educational Psychology, 95(1), 137-147.

Go, F. \& Mok, C. (1995). Hotel and tourism management education: Building a centre of excellence in Hong Kong. Tourism Recreation Research, 20(2), 46-57.

Gow, L. \& Kember, D. (1990). Does higher education promote independent learning? Higher Education, 19, 307-322.

Hofstede, G. \& Hofstede, J. (2005). Cultures and organization-software of the minds (2 ${ }^{\text {nd }}$ ed.). New York, McGraw-Hill.

Hu, C-T. (2002). China: Its people, its society, its culture. New Haven: HRAF Press.

Jia, W. (2001). The remarking of the Chinese character and identity in the $21^{\text {st }}$ century. London: Ablex Publishing.

Johnson, D.W. \& Johnson, R.T. (1999). Learning together and alone. London: Allyn and Bacon.

Kember, D. (2000). Misconceptions about the learning approaches, motivation and study practices of Asian students. Higher Education, 40, 99-121.

Kirkpatrick, D. (1998). A class-ic mistake. Retrieved from http://www.schoolreport.com/schoolreport/articles/AClassicMistake_6_98.htm on 20 October, 2004.

Marton, F. \& Saljo, R. (1996). On qualitative differences in learning, outcome and process II. British Journal of Educational Psychology, 46, 115-127.

Neuman, W.L. (2003). Social research methods: Qualitative and quantitative approaches. Boston: Allyn and Bacon.

Nisbett, R. E. (2003). The geography of thought: How Asians and Westerners think differently ...and why. Simon \& Schuster New York: Free Press.

Park, C. C. (2002). Crosscultural differences in learning style of secondary English learners. Bilingual Research Journal, 26(2), 213-229.

Phuong-Mai, N, Terlouw, C. \& Pilot, A. (2006). Culturally appropriate pedagogy: the case of group learning in a Confucian Heritage Culture context, International Education, 17(1), 1-19.

Robertson, M., Line, M., Jones, S. \& Thomas, S. (2000). International students' learning environments and perceptions: A case study using the Delphi Technique. Higher Education Research and Development, 19(1), 89-102.

Sama, L. M. \& Papamarcos, S. D. (2000). Hofstede's I-C Dimension as predictive of allocative behaviors: Meta-analysis. International Journal of Value-Based Management, 13, 173-188. 
Slavin, R. E. (1992). When and why does cooperative learning increase achievement? Theoretical and empirical perspectives. In Hertz-Lazarowitz, R. \& Miller, N. (Eds.), Interaction in cooperative Groups: The Theoretical Anatomy f Group Learning (pp. 145-173). Cambridge, UK: Cambridge.

Tang, C. (1991). Spontaneous collaborative learning: a new dimension in student learning experience? Paper presented at the $4^{\text {th }}$ European Association for Research on Learning and Institution Conference. Turku, Finland.

Thanh-Pham, TH, Gillies, R. \& Renshaw, P. (2009). Cooperative learning (CL) an academic achievement of Asian students: A true story. International Education Studies, 1(3), 82-88.

Thanh-Pham, T.H. (2008). The roles of teachers in implementing educational innovation: The case of implementing cooperative learning in Vietnam. Journal of Asian Social Science, 4(1), 3-10.

Triandis, H. (1995). Individualism and collectivism. Boulder, CO: Westviews.

Watson, S. B. \& Marshall, J.E. (1995). Heterogeneous grouping as an element of cooperative learning in an elementary science course. School Science and Mathematics, 8, 95: 401-406.

\section{Appendix 1}

\section{QUESTIONNAIRE SURVEY}

Student name:

Part I: Please rank each of the statement according to your point of view. Using the following scale circle your response:

1. How often do you have CL in your class?

Always Often Sometimes Seldom Never

2. Formats of CL used in class.

a. The teacher announces the topic. Then, students choose group members to discuss together then report in front of the class.
Always
Often
Sometimes
Seldom
Never

b. The teacher announces the topic. Then, students choose group members and then the teacher assesses the group work.
Always
Often Sometimes Seldom
Never

c. The teacher announces the topic, assigns students in groups, instructs students to work in group, asks students to evaluate each other and assesses the group product.
Always
Often
Sometimes
Seldom
Never

3. Cooperative learning is effective.
Strongly Agree
Agree
Undecided Disagree
Strongly Disagree

4. Cooperative learning improves students' knowledge and soft skills like self-confidence and communication.
Strongly Agree
Agree
Undecided Disagree
Strongly Disagree

5. I want to apply cooperative learning in my class.
Strongly Agree
Agree
Undecided Disagree
Strongly Disagree

\section{Part II: Please answer these following questions and explain your answers.}

How often do you learn in groups with your friends?

What are advantages and disadvantages of studying cooperatively?

How do you often study to cope with exams?

What barriers do you think hinder cooperative learning groups in your class? Explain why?

\section{Appendix 2}

\section{INTERVIEW QUESTIONS FOR TEACHERS}

Tell me about your use of cooperative learning.

How often do you apply cooperative learning in your class?

Describe how you start cooperative learning lessons. 
In your opinion, what is the main purpose of cooperative learning?

Help students develop soft skills

Help students remember texts

Help students understand texts deeply

When do you often use cooperative learning?

When you start a new lesson

When you want students review what has been taught

When you want to change learning environment

Tell me about barriers that you have to cope with when you apply cooperative learning.

Class size

Curriculum pressures

Workload sharing

What barrier do you think is the toughest and how do you do to limit these barriers?

Tell me about how you prepare your students for exams?

You guide students where to study for the exams

You ask students to study together to find extra information

Do you want to apply cooperative learning more often?

\section{Appendix 3}

\section{INTERVIEW QUESTIONS FOR STUDENTS}

Tell me how often your class use of cooperative learning.

Describe how your teacher often starts cooperative learning lessons.

In your opinion, what is the main purpose of cooperative learning?

Help students develop soft skills

Help students remember texts

Help students understand texts deeply

Tell me about barriers that you have to cope with when you apply cooperative learning.

Class size

Curriculum pressures

Workload sharing

What barrier do you think is the toughest and how do you do to limit these barriers?

Tell me about how you prepare for exams?

You study alone? Why?

You study with your friends in groups? Why?

Is it useful to join cooperative learning lessons before you have exams? Why 'yes'? Why 'no'?

Do you want to join cooperative learning more often? 
Table 1. Barriers of CL emerging from questionnaires and interview responses

\begin{tabular}{|c|c|c|}
\hline Categories & Problems & Raw themes \\
\hline \multirow[t]{3}{*}{ Class size } & (1) Noise & $\begin{array}{l}\text { Every class had more than one hundred students who could drive you mad. You } \\
\text { could not request them to sit still with their mouths shut during group work. Could } \\
\text { learning really take place under such a noisy classroom (teacher)? } \\
\text { All tables are tightly packed together. My group often overhear nearby groups' } \\
\text { discussions (student). }\end{array}$ \\
\hline & (2) Management & $\begin{array}{l}\text { Most students form groups with friends. Then they use the discussion time to start } \\
\text { chatting amongst themselves (teacher). }\end{array}$ \\
\hline & & $\begin{array}{l}\text { When the teacher joins one of the groups, that group would start the discussion. } \\
\text { When the teacher leaves the group, they start to gossip again (teacher). } \\
\text { Some group members are not self-disciplined when the teacher is not present } \\
\text { (student). }\end{array}$ \\
\hline \multirow[t]{3}{*}{$\begin{array}{l}\text { Curricula } \\
\text { coverage }\end{array}$} & (1) Time-consuming & $\begin{array}{l}\text { It is not easy to interrupt students' talking. When you see their passionate discussion, } \\
\text { it means they are mainly on task and you think: "Let them go on and give them a bit } \\
\text { more time". This might happen with several groups then at the end the time is } \\
\text { already been over (teacher). } \\
\text { Group work is fine after examinations when there is nothing left in the textbook. } \\
\text { Otherwise, with such a tight teaching schedule but limited time, you could not afford } \\
\text { the luxury of group work. Maybe it could be done once in a while when a certain } \\
\text { topic required plenty of sharing among the students (teacher). } \\
\ldots \text { it usually takes around } 15 \text { minutes for students to settle in their groups; then the } \\
\text { group needs some minutes to warm up...Eventually group work always burns my } \\
\text { lesson plan (teacher). }\end{array}$ \\
\hline & (2) Overloaded content & $\begin{array}{l}\text { We have to follow the curriculum. A certain amount of work needs to be completed } \\
\text { each day (teacher). }\end{array}$ \\
\hline & & $\begin{array}{l}\text { If we work in teams in class, then we have to do more lesson at home (student). } \\
\text { Students need to complete the whole textbook before they take exams (teacher). }\end{array}$ \\
\hline \multirow[t]{3}{*}{$\begin{array}{l}\text { Workload } \\
\text { division }\end{array}$} & (1) Unfairness & $\begin{array}{l}\text { But you couldn't help thinking why I am dealing with all the tasks from } \\
\text { summarizing to giving conclusion. If I don't, the whole group gets stuck and it } \\
\text { affects our achievement (student). } \\
\text { I just feel unfair when I give every member the same score because obviously some } \\
\text { members always do more than the others (teacher). }\end{array}$ \\
\hline & (2) Harmonious concerns & $\begin{array}{l}\text { Sometimes I am not quite sure of my group mates' explanation but I should "nod my } \\
\text { head" because if I strongly protest, I would destroy the group's good mood (student). } \\
\text { When you express opposite ideas, you should think that you may hurt your friends } \\
\text { (student). }\end{array}$ \\
\hline & & Harmony is important to working atmosphere (student). \\
\hline $\begin{array}{l}\text { Material } \\
\text { resource }\end{array}$ & Reading limitations & $\begin{array}{l}\text { We don't usually have extra materials for students to consult (teacher). } \\
\text { If we have more readings, we will bring different perspectives to group discussions } \\
\text { (student). }\end{array}$ \\
\hline $\begin{array}{l}\text { Face-to-face } \\
\text { discussion }\end{array}$ & Uncomfortable feelings & $\begin{array}{l}\text { Hard to be objective-personal feelings and friendship obstruct. I don't like analyzing } \\
\text { and criticizing friends' work (student). } \\
\text { The reason why I kept my questions for myself was ... because I didn't want to } \\
\text { embarrass the writer or start arguments (student). } \\
\text { It was so hard for somebody to hear that they need to rewrite ... because I knew they } \\
\text { have tried their best (student). } \\
\text { Its useful...but I found it very difficult to criticize someone's work especially with } \\
\text { them being friends (student). }\end{array}$ \\
\hline
\end{tabular}

